\title{
Impairment of executive function in Kenyan children exposed to severe falciparum malaria with neurological involvement
}

\author{
Symon M Kariuki ${ }^{1,2^{*}}$, Amina Abubakar ${ }^{1,3}$, Charles RJC Newton ${ }^{1,4}$ and Michael Kihara ${ }^{1,5}$
}

\begin{abstract}
Background: Persistent neurocognitive impairments occur in a fifth of children hospitalized with severe falciparum malaria. There is little data on the association between different neurological phenotypes of severe malaria (seizures, impaired consciousness and prostration) and impairments in executive function.

Methods: Executive functioning of children exposed to severe malaria with different neurological phenotypes $(\mathrm{N}=58)$ and in those unexposed $(\mathrm{N}=56)$ was examined using neuropsychological tests such as vigilance test, test for everyday attention test for children (TEA-Ch), contingency naming test (CNT) and self-ordered pointing test (SOPT). Linear regression was used to determine the association between neurological phenotypes of severe malaria and executive function performance scores, accounting for potential confounders.

Results: Children with complex seizures in severe malaria performed more poorly than unexposed controls in the vigilance (median efficiency scores (interquartile range) $=4.84(1.28-5.68)$ vs. $5.84(4.71-6.42), P=0.030$ ) and SOPT (mean errors (standard deviation) $=29.50$ (8.82) vs. $24.80(6.50), P=0.029)$ tests, but no differences were observed in TEA-Ch and CNT tests. Performance scores for other neurological phenotypes of severe malaria were similar with those of unexposed controls. After accounting for potential confounders, such as child's age, sex, schooling; maternal age, schooling and economic activity; perinatal factors and history of seizures, complex seizures remained associated with efficiency scores in the vigilance test (beta coefficient $(\beta)(95 \%$ confidence interval $(C \mid))=-0.40$ $(-0.67,-0.13), P=0.006)$ and everyday attention scores of the TEA-Ch test $(\beta(95 \% \mathrm{Cl})=-0.57(-1.04,-0.10), P=0.019)$; the association with SOPT error scores was weak $(\beta(95 \% \mathrm{Cl})=4.57(-0.73-9.89), P=0.089)$. Combined neurological phenotypes were not significantly associated with executive function performance scores.

Conclusion: Executive function impairment in children with severe malaria is associated with specific neurological phenotypes, particularly complex seizures. Effective prophylaxis and management of malaria-associated acute seizures may improve executive functioning performance scores of children.
\end{abstract}

Keywords: Children, Executive functioning, Falciparum malaria, Kenya, Acute seizures

\section{Background}

Plasmodium falciparum malaria is the most common parasitic infection for the central nervous system in endemic areas, and seizures and impaired consciousness (cerebral malaria) are the main neurological manifestations [1]. Cerebral malaria and malaria-associated seizures give rise to neurocognitive impairments, particularly in

\footnotetext{
* Correspondence: skariuki@kemri-wellcome.org

'KEMRI/Wellcome Trust Collaborative Research Programme, P.O. Box 230, 80108 Kilifi, Kenya

${ }^{2}$ Nuffield Department of Medicine, University of Oxford, Oxford, UK

Full list of author information is available at the end of the article
}

the speech, language and memory domains [2]. Persistent neurocognitive impairments have been reported in $23 \%$ of children hospitalized with falciparum malaria in rural Kenya [2]. These impairments may be related to features or phenotypes of neurological involvement (seizures, impaired consciousness and prostration) common in severe malaria [3].

It has been suggested that malaria infection produces damage to the frontal lobes and which is associated with executive function deficits. Executive functions are specific neuropsychological skills defined as self-regulatory 
functions responsible for organizing and directing cognitive activities, emotional response and behaviour [4]. These functions are useful in directing day-to-day activities, and play a salient role in shaping long-term outcomes e.g. scholastic achievement. Despite the salient role of executive function skills, no previous study has systematically investigated the impact of different mutually exclusive phenotypical representation of malarial disease on executive functions. The few studies looking at various aspects of executive function indicate the potential negative impact of malarial infection on executive function. For instance, a previous study in Kilifi, Kenya examined executive functioning following exposure to falciparum malaria in general, but not different phenotypes, and found that the mean scores of attention/visual search were inferior in the affected group compared to controls (42.5 vs. 45.6, $\mathrm{p}=0.03$ ) [5]. In another study, from a different sample in Kilifi, working memory impairment (considered a sub-domain of executive functioning) was examined in children hospitalized with falciparum malaria encephalopathy [6]. In this study, paediatric falciparum malaria was associated with impairments in recall and recognition, but not in prospective memory [6], implicating other parts of the brain other than the extended hippocampal system.

It is recognized that memory recall problems may be a reflection of retrieval deficits often classified under executive functioning, which is mainly mediated by the frontal lobe [7]. Other cognitive processes involved in executive functioning are planning, reasoning, attention and implementation of tasks [8]. Involvement of extra-hippocampal damage during malaria infection was hypothesized in a previous study [6], although it was not possible to conclude whether the observed recall impairments were a marker of executive dysfunctioning because of the tool used. The diffuse pattern of involvement found in severe falciparum malaria [9], may damage the frontal lobe resulting in impairments in executive functioning.

A number of risk factors have been associated with poor cognition: environmental and genetic factors [10], clinical factors such as coma and hypoglycaemia [11], and perinatal insults [12]. Other important risk factors of cognitive functioning include malnutrition [13] and schooling status [14]. It can be hypothesized that executive functioning in children with severe malaria is related to the specific phenotypes of malaria with neurological involvement (seizures, impaired consciousness and prostration), but which may be modified by other risk factors.

The performance of executive function in school-aged children who had been exposed to different phenotypes of severe falciparum malaria with neurological involvement was examined to characterize the patterns of executive dysfunction.

\section{Methods}

\section{Study site and population}

Children hospitalized to Kilifi District Hospital (KDH) with severe falciparum malaria and unexposed children selected randomly from the Kilifi Health and Demographic Surveillance System (KHDSS) database were studied. $\mathrm{KDH}$ is the only district level hospital in the entire KHDSS, which has a population of about 250,000 people [15]. This hospital draws most admissions from the local populations, and the commonest infectious causes of childhood admissions are malaria, bacterial and viral infections (including HIV) [16].

\section{Study sample and definition of terms}

The study participants were 114 children aged between six and nine years, 58 of whom had been hospitalized with various malaria-related complications i.e. severe malaria with neurological involvement, and 56 unexposed children, without a history of underlying encephalopathy, who served as population controls, and were similar with the cases in terms of sex, and sociodemographic characteristics and school attendance (Table 1). The causes of hospitalization for the exposed group were severe malaria with impaired consciousness (defined as unarousable coma [Blantyre Coma Score s2] [17] in 30 children, complex symptomatic seizures (defined as repetitive seizures during one illness, focal seizures and/or prolonged seizures lasting $>15$ minutes $[18,19]$ but in conscious patients) in 15 , prostration (defined as inability to sit, drink or breastfeed; but conscious) in 9 and seizures with fever in 4 . The hospitalized children had been managed using the national and WHO guidelines [20].

\section{Assessment of neurocognition}

Children were invited for neuropsychological assessments 1-2 years after discharge from $\mathrm{KDH}$, where they had been treated for severe malaria [21]. Sociodemographic and medical history information was collected during assessments. All children (those exposed and unexposed to falciparum malaria) were assessed for cognitive performance on the following domains: working memory, attention (including sustained attention), executive function (including planning), and vigilance. Working memory and attention were assessed with the self-ordered pointing test and the vigilance (a computerized visual search) test. Executive functions or planning ability was tested using the contingency naming test, while sustained attention was tested using score or test for everyday attention for children (TEA-Ch).

\section{Assessment procedure}

The assessment scales used in study are well-standardized neuropsychological tests, which were culturally adapted, 
Table 1 The distribution of sociodemographic and medical history characteristics among those exposed to severe malaria and unexposed controls

\begin{tabular}{lccc}
\hline Characteristic & Exposed (N= 58) & Unexposed (N= 56) & Comparison \\
\hline Median age in years (IQR) & $6.0(6.0-7.0)$ & $6.0(6.0-8.0)$ & $Z=-1.72, P=0.085$ \\
Male sex (\%) & $27(46.6)$ & $27(48.2)$ & $X^{2}=0.03, P=0.859$ \\
Home delivery (\%) & $43(81.1)$ & $48 / 54(88.9)$ & $X^{2}=1.27, P=0.261$ \\
Perinatal problems (\%) & $15(25.8)$ & $11(19.1)$ & $X=0.63, P=0.429$ \\
Incomplete immunization (\%) & $40 / 41(97.6)$ & $35 / 36(97.2)$ & $P=1.00^{\mathrm{a}}$ \\
Median maternal age in years (IQR) & $34.0(29.0-44.0)$ & $32.0(27.5-37.5)$ & $Z=-0.86, P=0.390$ \\
Mother did not attend school (\%) & $29 / 52(54.7)$ & $11 / 49(22.5)$ & $X^{2}=0.01, P=0.929$ \\
Unschooled dad (\%) & $14 / 51(27.5)$ & $24 / 51(47.1)$ & $X^{2}=0.33, P=0.564$ \\
Lack of maternal economic activity (\%) & $19 / 51(37.3)$ & $12 / 46(26.1)$ & $X^{2}=1.01, P=0.316$ \\
Lack of paternal economic activity (\%) & $12 / 48(25.0)$ & $X^{2}=0.02, P=0.904$ \\
Child attends school (\%) & $39(67.2)$ & $2(1-3)$ & $X^{2}=0.33, P=0.564$ \\
Median number of previous hospitalization, IQR (\%) & $2(1-3)$ & $Z=1.70, P=0.088$ \\
History of seizures (\%) & $6 / 54(11.1)$ & $X^{2}=0.11, P=0.740$ \\
\hline
\end{tabular}

${ }^{\text {a }}$ isher's exact test; $\mathrm{IQR}=$ interquartile range.

and their psychometric properties evaluated and have been observed to retain good psychometric properties [22].

\section{Self-ordered pointing test (SOPT)}

The test requires non-spatial executive abilities in order to organize and carry out and monitor a sequence of responses [23]. The SOPT is a non-verbal test involving three trials of increasing difficulty, with each trial comprising drawings of locally available materials such as drums, taps and animals [22]. In each trial the order of the arrangement of the drawings is changed. The participants were instructed in the local language (Giriama), to point to a particular drawing from a group of 8,10 , or 12 , and the number of errors made was noted. The participants are required to identify all the drawings during all the three trials, by touching each once. No feedback is given to the child during the test, but they were reminded to point a different place if they kept pointing to the same drawing in each trial. A six-drawings, trial test was presented to the patient before the actual trials for practice, to ensure that the instructions are well understood. All children completed all the tests in a fixed order. The main outcome is usually the total number of errors observed in all the three group-items $(8,10$ or 12$)$ during the three trials.

\section{Contingency naming test (CNT)}

$\mathrm{CNT}$ is comprised of four trials in which one names two shapes (with one small embedded inside the big one) and colours [24]. The test is sensitive and useful in testing the function of the frontal lobe i.e. speed of retrieving names and mental set shifting with changing rules/instructions [24]. The first two trials are simple as they involve automatic naming of colours, both of which requires making of a decision under a contingency rule in the third and fourth trial. In trial 1, children were asked to name the colours of the shapes while in trial 2, the child names the external shape. In trial 3, which is a switching task, children were asked to name the colour of the shape if the internal and external shapes matched and to name the external shape if the shapes didn't match. Finally, in trial 4 children retained the rules of trial 3 but the rules were reversed i.e. if the internal and external shapes match, the shape was to be named and if they don't, the colour was to be named. Due to the complexity of the task, total errors, time and efficiency was computed for the first three tasks separately and then again for all the four tasks.

\section{Score/ test for everyday attention test for children (TEA-Ch)}

Score is a measure of a child's everyday attention utilizing auditory attention [7]. Children were asked to place beads repetitively on a designated place every time a tone was heard from a15-minute audio tape. The consisted of 10 trials each involving presentation of 9-15 identical tones lasting about 350 milliseconds, which are separated by silent inter-stimulus intervals ranging between 500 milliseconds to 5,000 milliseconds. Normally children are asked to silently count the tones, but for appropriateness in this rural Kenyan setting, children were asked to place beads in alternate sectors of an apportioned plate every time a tone was produced. Correct performance of the task is earned a point and summated for all trials at the end of the response. Children with 
higher response rates were assumed to have better sustained attention.

\section{Computerized visual search task (Vigilance)}

Vigilance is a computerized perceptual task requiring attention and involves an active visual for a particular object (the target) among other objects (the distracters) [25]. Children were asked to depress a button when they saw a stick figure of a man with all limbs and not depress if it was a woman or had some limbs missing. The task generated (a) errors of omission (sustained attention), when the child forgot to depress the button on the presentation of the target stimulus and (b) errors of commission (impulsivity), when the child depressed the button without the presentation of the target stimulus. Both errors were expressed as a percentage. The efficiency score was also computed taking into account the reaction speed, number of correct responses and number of errors.

\section{Statistical analysis}

All analyses were performed using STATA (version 11, Stata Corp, TX, USA). The raw scores were nonparametric and thus the differences between the exposed and unexposed groups were performed using MannWhitney $U$ test, but Student t-test was used for SOPT whose scores were parametric. The differences in the proportion of categorical variables between the exposed and unexposed groups were computed using Pearson's ChiSquare test and Fisher's exact where appropriate.

Performance scores for all tests except SOPT were nonparametric and were thus square root-transformed to achieve normality. The univariate analysis of the association between different neurological phenotypes of severe malaria and the scores for executive function tests was determined using linear regression. The multivariate analysis of the association between different phenotypes of severe malaria and the scores for executive function tests was determined using a linear regression model with child's age, sex, schooling; and maternal schooling and economic activity; perinatal adverse events, previous hospitalizations and history of seizures as potential confounders. Interaction between phenotypes of severe malaria and adverse perinatal events with regards to poor executive functioning scores was tested a priori to determine whether associations should be stratified by presence or absence of perinatal events. A two-tailed $\mathrm{p}$-value of $\leq 0.05$ is considered significant for this analysis.

\section{Results}

All background social demographic characteristics and medical history were similar for the children exposed to neurological phenotypes of severe malaria, and those unexposed (Table 1).

\section{Comparison between combined exposed group and controls}

Overall there was no difference in performance scores between the combined neurological phenotypes and controls in all the four tests: the Vigilance test, TEA-Ch, SOPT and CNT (Table 2). In a linear regression model adjusted for potential confounders, combined neurological phenotypes were weakly associated with errors of commission in the vigilance test (beta coefficient ( $\beta$ ) (95\% confidence interval $(C I))=-0.06(-0.00-0.13), P=0.057)$, but no significant associations were observed for other tests. There was no evidence of interaction between adverse perinatal events and neurological phenotypes of severe malaria with regards to performance scores for all tests, thus associations are presented without stratifying by adverse perinatal events.

\section{Comparison between specific neurological phenotypes of severe malaria and controls}

The Vigilance test efficiency scores were higher in the exposed group than controls for complex seizures $(\mathrm{z}=2.17$, $\mathrm{P}=0.030$ ) (Figure 1), but not for impaired consciousness $(\mathrm{P}=0.865)$, prostration $(\mathrm{P}=0.849)$ and seizures with fever $(P=0.223)$. Based on linear regression, complex seizures remained associated with efficiency scores in the multivariate analysis, which accounted for potential confounders $(\beta$ (95\% (CI) $=-0.40(-0.67,-0.13), \mathrm{P}=0.030)$ (Table 3).

The errors of commission scores in the Vigilance test were higher in the exposed group than controls for complex seizures $(\mathrm{z}=-3.337, \mathrm{P}=0.007)$, but not for impaired consciousness $(\mathrm{P}=0.913)$, prostration $(\mathrm{P}=0.865)$ and seizures with fever $(P=0.485)$. In a linear regression model accounted for potential confounders, complex seizures remained associated with errors of commission ( $\beta \quad(95 \% \quad(\mathrm{CI})=0.18 \quad(0.08-0.28), \quad \mathrm{P}=0.001)$, but other neurological phenotypes were not [impaired consciousness $(P=0.731)$, prostration $(P=0.519)$ and seizures with fever $(\mathrm{P}=0.816)]$. Compared with the unexposed group, the errors of omission (sustained attention) scores were different for complex seizures $(\mathrm{z}=2.29, \mathrm{P}=0.022)$, but not for impaired consciousness $(\mathrm{P}=0.457)$, malaria prostration $(\mathrm{P}=0.562)$ and seizures with fever $(\mathrm{P}=0.678)$. However in an adjusted linear regression model, errors of omission were not associated with specific neurological phenotypes of severe malaria. The overall average time to correct response differed between the exposed and unexposed group for complex seizures $(\mathrm{z}=2.492$, $\mathrm{P}=0.012)$, but not for impaired consciousness $(\mathrm{P}=0.324)$, prostration $(\mathrm{P}=0.976)$ and seizures with fever $(\mathrm{P}=0.552)$. However in an adjusted linear regression model average time to correct response was not associated with specific neurological phenotypes of severe malaria.

The scores for errors in TEA-Ch were not different between the exposed and unexposed group for complex 
Table 2 The differences in median scores of vigilance test and TEA-Ch test among the four exposed-groups, and between exposed and unexposed controls

\begin{tabular}{|c|c|c|c|c|c|c|c|}
\hline \multirow[t]{2}{*}{ Description } & \multicolumn{4}{|c|}{ Cases } & \multirow{2}{*}{$\begin{array}{c}\text { Controls } \\
\text { Unexposed }\end{array}$} & \multirow[t]{2}{*}{ Comparison $^{\mathrm{a}}$} & \multirow[t]{2}{*}{ Comparison $^{b}$} \\
\hline & Cerebral malaria & Malarial seizures & Malarial prostration & Malarial seizures with fever & & & \\
\hline \multicolumn{8}{|l|}{ Vigilance test } \\
\hline Omission $^{c}$ & $0.63(0.45-0.71)$ & $0.46(0.32-0.66)$ & $0.66(0.64-0.86)$ & $0.71(0.47-0.87$ & $0.64(0.50-0.75$ & $X^{2}=6.08, P=0.108$ & $Z=1.13, P=0.259$ \\
\hline Commission $^{c}$ & $0.40(0.28-0.50)$ & $0.60(0.37-0.78)$ & $0.37(0.32-0.46)$ & $0.53(0.30-0.63)$ & $0.35(0.18-0.49)$ & $X^{2}=7.10, P=0.069$ & $Z=-1.22, P=0.222$ \\
\hline Average time & $11.5(10.9-12.5)$ & $9.6(7.7-11.9)$ & $11.6(10.7-11.9)$ & $11.2(9.9-11.7)$ & $11.6(10.6-12.4)$ & $X^{2}=8.351, P=0.039$ & $Z=0.50, P=0.616$ \\
\hline Efficiency & $5.6(5.1-6.1)$ & $4.9(2.3-5.7)$ & $5.9(5.5-6.3)$ & $4.7(4.3-5.5)$ & $5.9(4.8-6.8)$ & $X^{2}=6.265, P=0.099$ & $Z=0.93, P=0.351$ \\
\hline \multicolumn{8}{|c|}{ Test of everyday attention for children (TEA-Ch) test } \\
\hline Median test total (IQR) & $5.0(4.0-9.0)$ & $3.5(3.0-7.0)$ & $7.0(5.0-9.0)$ & $4.0(2.5-5.0)$ & $7.0(4.0-10.0)$ & $X^{2}=4.62, P=0.198$ & $Z=0.46, P=0.644$ \\
\hline \multicolumn{8}{|c|}{ Contingency Naming Test (CNT) } \\
\hline Median total error1 (IQR) & $0(0-2.0)$ & $0(0-2.0)$ & $0(0-1.0)$ & $0(0-0.5)$ & $0(0-2.0)$ & $X^{2}=1.57, P=0.667$ & $Z=1.03, P=0.303$ \\
\hline Median efficiency1 (IQR) & $1.5(0.8-1.9)$ & $1.0(0.7-1.4)$ & $1.3(1.2-1.9)$ & $1.4(1.2-1.7)$ & $1.3(0.8-1.8)$ & $X^{2}=3.70, P=0.295$ & $Z=-1.08, P=0.279$ \\
\hline Median total error2 (IQR) & $1.0(0-4.0)$ & $2.0(0-6.0)$ & $1.0(0-3.0)$ & $0(0.9 .5)$ & $1.0(0-3.5)$ & $X^{2}=1.27, P=0.735$ & $Z=0.20, P=844$ \\
\hline Median efficiency2 (IQR) & $0.5(0.2-0.7)$ & $0.3(0.1-0.6)$ & $0.5(0.4-0.7)$ & $0.7(0.4-0.8)$ & $0.5(0.2-0.8)$ & $X^{2}=2.86, P=0.413$ & $Z=-0.61, P=0.539$ \\
\hline Median total error3 (IQR) & $12.0(9.0-15)$ & $13(9.0-16.0)$ & $11.0(10.0-16.0)$ & $13.5(10.0-17.0)$ & $12.0(9.0-15.0)$ & $X^{2}=0.35, P=0.950$ & $Z=-0.09, P=0.927$ \\
\hline Median efficiency3 (IQR) & $0.09(0.07-0.14)$ & $0.10(0.06-0.12)$ & $0.11(0.09-0.12)$ & $0.09(0.07-0.15)$ & $0.10(0.07-0.13)$ & $X^{2}=1.33, P=0.721$ & $Z=-0.68, P=0.499$ \\
\hline Median total error4 (IQR) & $14.0(12.0-15.0)$ & $14.0(12.0-16.0)$ & $14.0(12.0-15.0)$ & $15.5(13.5-17.0)$ & $13.0(12.0-15.0)$ & $X^{2}=1.45, P=0.694$ & $Z=-0.62, P=0.534$ \\
\hline Median efficiency4 (IQR) & $0.05(0.04-0.07)$ & $0.04(0.03-0.06)$ & $0.05(0.04-0.06)$ & $0.05(0.04-0.06)$ & $0.05(0.04-0.06)$ & $X^{2}=1.05, P=0.790$ & $Z=-0.75, P=0.456$ \\
\hline \multicolumn{8}{|c|}{ Self-ordered pointing test (SOPT) } \\
\hline Total errors & $23.0(19.0-31.0)$ & $32.0(22.0-35.0)$ & $26.0(25.0-29.0)$ & $28.0(24.0-36.0)$ & $24.0(18.0-29.0)$ & $X^{2}=3.86, P=0.277$ & $\mathrm{t}=-1.44, \mathrm{P}=0.152$ \\
\hline
\end{tabular}

${ }^{a}$ Comparison among the four groups of cases using Kruskal-Wallis test; ${ }^{b}$ Comparison between the combined exposed groups and unexposed controls was done using Mann-Whitney $U$ test, but student $t$-test for SOPT; CProportion of participants who made errors of either omission or commission. 


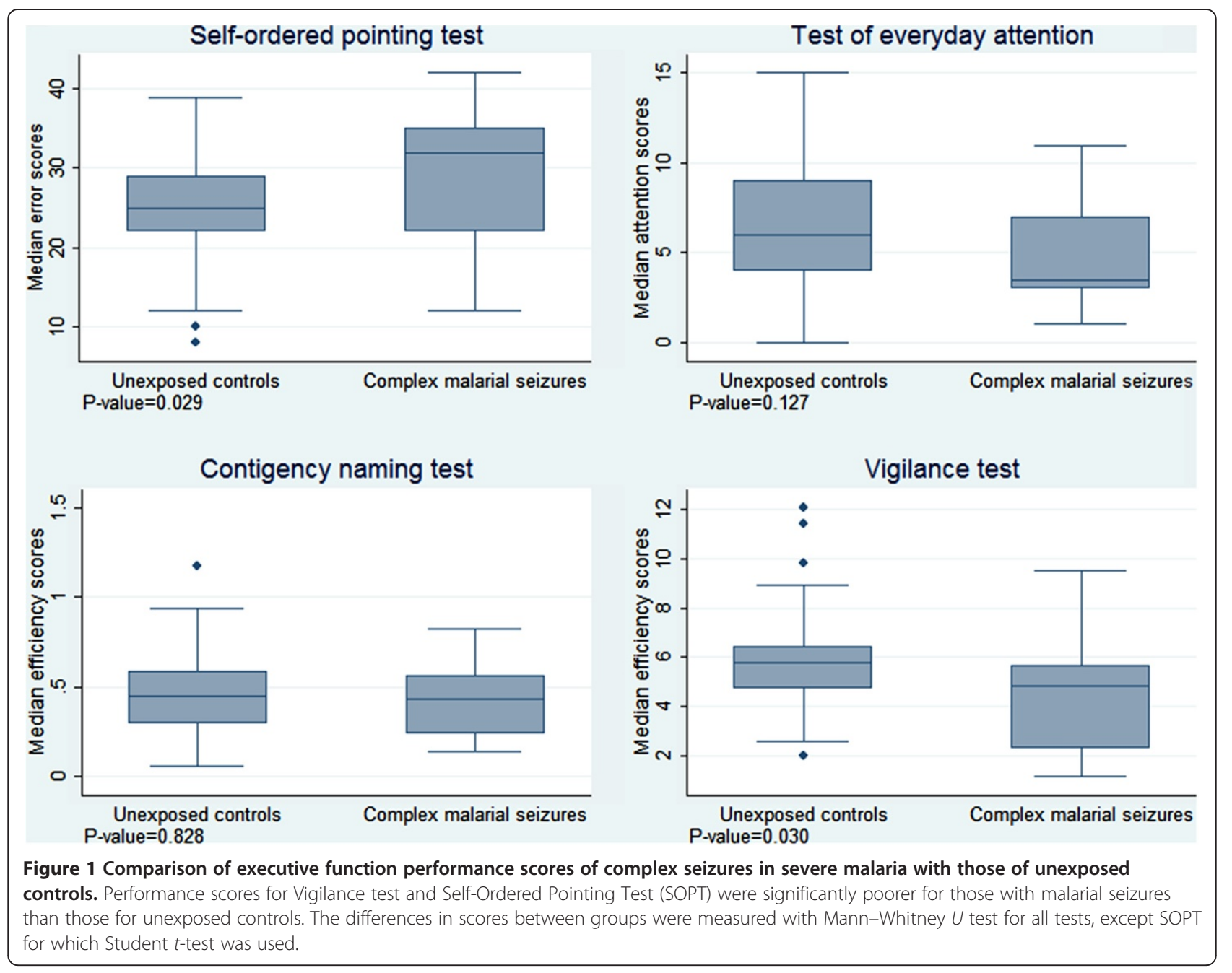

seizures group $(, \mathrm{P}=0.127$ ) (Figure 1 ), impaired consciousness $(P=0.771)$, prostration $(P=0.447)$, seizures with fever $(\mathrm{P}=0.165)$. Based on linear regression, complex seizures were associated with attention scores of the TEA-Ch test in the adjusted analysis $(\beta(95 \%(\mathrm{CI})=-0.57$ $(-1.04,-0.10), \mathrm{P}=0.019)$ (Table 3).

Compared to unexposed controls complex seizures group performed significantly more errors in SOPT $(t=-2.24$, $\mathrm{P}=0.029$ ) (Figure 1), but others did not [impaired consciousness $(P=0.771)$, prostration $(P=0.562)$, seizures with fever $(P=0.133)]$. However, based on linear regression, complex seizures were weakly associated with efficiency scores in the adjusted analysis $(\beta(95 \%(\mathrm{CI})=4.57$ $(-0.73-9.89), \mathrm{P}=0.089)$ ) (Table 3).

There were no differences in the average errors committed in the four CNT trials between the exposed and unexposed for all clinical sub-groups: complex seizures $(\mathrm{P}=0.993)$, impaired consciousness $(\mathrm{P}=0.801)$, prostration $(\mathrm{P}=0.590)$ and seizures with fever $(\mathrm{P}=0.884)$. Average errors were not associated with neurological phenotypes in a linear regression model adjusted for potential confounders. Again there were no differences in the average efficiency in the fours CNT trials for all clinical sub-groups compared to controls: complex seizures ( $\mathrm{P}=0.828)$, impaired consciousness $(\mathrm{P}=0.196)$, prostration $(P=0.246)$ and seizures with fever $(P=0.279)$. In a linear regression model adjusted for potential confounders, average efficiency in the fours CNT trials were not associated with neurological phenotypes of severe malaria (Table 3).

\section{Discussion}

This study set out to determine if exposure to different neurological phenotypes of severe malaria is associated with impairments of executive functioning in children. Children exposed to complex seizures in severe malaria made more errors of commission and omission, and were less efficient in the vigilance test, and erred more in the SOPT test compared to the unexposed group, with most of these associations remaining significant after accounting for potential confounders. These pattern of results 
Table 3 Univariate and multivariate analysis of the association between different neurological phenotypes of severe malaria and scores for executive

\section{functioning tests in children}

\begin{tabular}{|c|c|c|c|c|c|}
\hline $\begin{array}{l}\text { Phenotypes of severe } \\
\text { malaria }\end{array}$ & $\begin{array}{l}\text { Vigilance efficiency } \\
\text { scores, } \beta \text { ( } 95 \% \mathrm{Cl})\end{array}$ & $\begin{array}{l}\text { TEA-Ch test total } \\
\text { scores, } \beta(95 \% \mathrm{Cl})\end{array}$ & $\begin{array}{l}\text { Contingency naming test average } \\
\text { total error scores, } \beta(95 \% \mathrm{Cl})\end{array}$ & $\begin{array}{l}\text { Contingency naming test average } \\
\text { efficiency scores, } \beta(95 \% \mathrm{Cl})\end{array}$ & $\begin{array}{l}\text { Self-ordered pointing test, } \\
\qquad \beta(95 \% \mathrm{Cl})\end{array}$ \\
\hline $\begin{array}{l}\text { Impaired consciousness: } \\
\text { unadjusted model }\end{array}$ & $0.02(-0.12-0.18) ; P=0.734$ & $0.09(-0.33-0.51) ; P=0.667$ & $-0.07(-0.28-0.14) ; P=0.494$ & $0.07(-0.02-0.16) ; P=0.110$ & $0.47(-2.73-3.67) ; P=0.771$ \\
\hline $\begin{array}{l}\text { Impaired consciousness: } \\
\text { adjusted model }\end{array}$ & $0.03(-0.14-0.20) ; P=0.756$ & $-0.40(-0.81-0.01) ; P=0.058$ & $0.08(-0.35-0.19) ; P=0.542$ & $0.06(-0.06-0.18) ; P=0.329$ & $0.99(-3.12-5.11) ; P=0.628$ \\
\hline $\begin{array}{l}\text { Complex seizures: } \\
\text { unadjusted model }\end{array}$ & $-0.35(-0.59-0.10) ; P=0.006$ & $-0.27(-0.81-0.27) ; P=0.318$ & $-0.04(-0.36-0.28) ; P=0.808$ & $-0.01(-0.12-0.12) ; P=0.919$ & $4.70(0.50-8.90) ; P=0.029$ \\
\hline $\begin{array}{l}\text { Complex seizures: } \\
\text { adjusted model }\end{array}$ & $-0.47(-0.67-0.13) ; P=0.006$ & $-0.57(-1.04-0.10) ; P=0.019$ & $-0.59(-0.20-0.08) ; P=0.411$ & $0.10(-0.32-0.52) ; P=0.629$ & $4.57(-0.73-9.89) ; P=0.089$ \\
\hline $\begin{array}{l}\text { Seizures with fever: } \\
\text { unadjusted model }\end{array}$ & $-0.16(-0.53-0.21) ; P=0.377$ & $-0.44(-1.40-0.52) ; P=0.361$ & $0.07(-0.46-0.60) ; P=0.802$ & $0.09(-0.10-0.27) ; P=0.342$ & $5.20(-1.64-12.05) ; P=0.133$ \\
\hline $\begin{array}{l}\text { Seizures with fever: } \\
\text { adjusted model }\end{array}$ & $-0.06(-0.50-0.37) ; P=0.763$ & $-0.42(-1.34-0.50) ; P=0.352$ & $0.18(-0.62-0.98) ; P=0.647$ & $0.04(-0.21-0.29) ; P=0.746$ & $2.72(-6.07-2.59) ; P=0.529$ \\
\hline $\begin{array}{l}\text { Prostration: unadjusted } \\
\text { model }\end{array}$ & $-0.00(-0.25-0.25) ; P=0.994$ & $0.33(-0.35-1.01) ; P=0.339$ & $-0.05(-0.42-0.33) ; P=0.800$ & $0.10(-0.03-0.22) ; P=0.142$ & $1.31(-3.19-5.82) ; P=0.562$ \\
\hline $\begin{array}{l}\text { Prostration: adjusted } \\
\text { model }\end{array}$ & $-0.01(-0.26-0.25) ; P=0.963$ & $0.21(-0.38-0.81) ; P=0.474$ & $-0.11(-0.62-0.39) ; P=0.653$ & $0.10(-0.06-0.25) ; P=0.205$ & $1.59(-3.86-7.05) ; P=0.555$ \\
\hline $\begin{array}{l}\text { All phenotypes: } \\
\text { unadjusted model }\end{array}$ & $-0.08(-0.23-0.05) ; P=0.219$ & $0.01(-0.34-0.34) ; P=0.989$ & $-0.05(-0.23-0.12) ; P=0.575$ & $0.06(-0.01-0.13) ; P=0.090$ & $1.98(-0.74-4.69) ; P=0.152$ \\
\hline $\begin{array}{l}\text { All phenotypes: } \\
\text { adjusted model }\end{array}$ & $-0.13(-0.13-0.04) ; P=0.137$ & $-0.29(-0.66-0.07) ; P=0.109$ & $-0.03(-0.26-0.20) ; P=0.800$ & $0.04(-0.05-0.13) ; P=0.408$ & $2.00(-1.28-5.29) ; P=0.229$ \\
\hline
\end{tabular}

TEA = test of everyday attention; $\beta$ = beta coefficient; $\mathrm{Cl}$ = confidence interval; associations were performed using linear regression, with multivariate analysis adjusted for a child's age, sex, schooling; maternal age, schooling and economic activity; perinatal adverse events and history of seizures. 
provide initial evidence that severe malaria especially when complicated with seizures negatively impact on executive functions.

The weak association between executive function scores and the combined different phenotypes of neurological involvement, suggests that executive function is affected by specific neurological phenotypes of severe malaria and that the association in previous studies may have been explained by some of these phenotypes [5]. This supposition was examined in mutually exclusive neurological phenotypes of severe malaria, and complex seizures were particularly associated with poor scores for a number of executive function tests.

\section{Role of seizures in impairments of executive function}

Differences in cognitive scores between the complex seizures (but not other phenotypes) and unexposed group were consistently documented with a number of tests. The significant independent association between malaria seizures and efficiency scores of the vigilance test, which assessed errors of omission (sustained attention) and commission, suggests that seizures in malaria affect sustained attention and impulsivity in children. This is further supported by the independent association between errors of commission and complex malarial seizures in this study. Other previous studies have associated seizures and attention/impulsivity problems [26], although some seizures had non-malarial aetiologies [27]. Additionally, every day attention, which is related to working memory, was worse in complex seizures than unexposed controls after accounting for potential confounders. Seizures did not appear to affect working memory in a previous study [6], which used different tools that could not investigate the effects of seizures on impulsivity and sustained and everyday attention.

Working memory may be affected by complex seizures in malaria because of the more errors observed in this group compared to unexposed children in the SOPT test. This conclusion was further supported by the trend towards significance in the adjusted analysis. A previous study [6], using a different cohort, concluded that impairments in recall (measured with a different tool) in severe malaria were not related to hippocampus, and this present study suggests possible involvement of the frontal lobe which mediates executive functions. However, neuroimaging studies were not available during the period of the study to confirm this supposition.

The mechanisms for the executive function impairment following seizures in malaria is not fully understand. Seizures may cause direct neuronal damage, compounded by the pathophysiology of impaired consciousness that may be related to the seizures and/or malaria. Therefore, the lack of an association between impaired consciousness alone and executive function scores in this study may imply that the impairments documented in the previous studies of cerebral malaria [28] may be related to seizures which occur in over $80 \%$ of children with cerebral malaria [29]. The underlying genetic predisposition or neurological impairment may also be a determining factor [30]. It is known executive function is largely mediated in the frontal lobe but neuroimaging studies to identify the affected structures are required since damage to temporal lobe may extend to the frontal region [31].

\section{Strengths and limitations}

The strength of this study lies on multifaceted neurocognitive assessment tools that are likely to tap different components of executive functioning at the same time. Single and simple executive tests have been faulted because of their low predictive value of how one performs in another different test or in the real life situation [8]. This approach allows for more confidence in our conclusions.

Executive performance in different neurological phenotypes of malaria is provided and their different pathogenetic mechanisms can easily be related to the observed psychopathologies. The multivariate analysis is accounted for several potential confounders to ensure that the differences measured reflect as much as possible the effect of exposure to different phenotypes of severe malaria. The tests used were validated in the local population and found to possess good psychometric properties [22]. However, the use of the specific neurological phenotypes was associated with small sample sizes which could have affected the power of the study. There was no data on intelligent quotients of children in the study, but school attendance was accounted for, which like intelligence, can influence neurocognitive performance [22]. Some tests such as CNT may have been difficult to all children and thus the lack of significant differences should be interpreted carefully. Data on nutritional status was not obtained, although it was not associated with test scores in a previous validation study of these tests in the same settings [22].

In conclusion, this study confirms that complex seizures in severe falciparum malaria are associated with impairments in executive functioning, suggesting possible frontal lobe involvement. Future larger studies are required to confirm these findings, accounting for potential confounders. The impairments should be assessed with more than one test since many specific cognitive components are involved, particularly impulsivity, working memory and sustained attention.

\section{Competing interests}

The authors declare that they have no competing interests.

\section{Authors' contributions}

SK formulated research questions, analysed the data, and wrote the first draft of the manuscript. AA helped with data analysis and revision of the manuscript. CN suggested and designed the study, helped with data analysis 
and critically reviewed the subsequent drafts of the manuscript. MK designed the study, collected data, helped with data analysis and reviewed the subsequent drafts of the manuscript. All authors approved the final version of the manuscripts.

\section{Acknowledgements}

This study is supported by the Wellcome Trust Senior Fellowship (083744) to CN. SK is supported by the Wellcome Trust, through a Research Training Fellowship (099782). We thank the clinical assessment team for helping with data collection and Rachael Odhiambo for data storage. The paper is published with the permission of the director of KEMRI

\section{Author details}

KEMRI/Wellcome Trust Collaborative Research Programme, P.O. Box 230, 80108 Kilifi, Kenya. ${ }^{2}$ Nuffield Department of Medicine, University of Oxford, Oxford, UK. ${ }^{3}$ Department of Psychology, Lancaster University, Lancaster, UK ${ }^{4}$ Department of Psychiatry, University of Oxford, Oxford, UK. ${ }^{5}$ Department of Psychology, United States International University, Nairobi, Kenya.

Received: 18 May 2014 Accepted: 14 September 2014

Published: 16 September 2014

\section{References}

1. Newton CR, Warrell DA: Neurological manifestations of falciparum malaria. Ann Neurol 1998, 43:695-702.

2. Carter JA, Mung'ala-Odera V, Neville BGR, Murira G, Mturi N, Musumba C, Newton CRJC: Persistent neurocognitive impairments associated with severe falciparum malaria in Kenyan children. J Neurol Neurosurg Psychiatry 2005, 76:476-481

3. Idro R, Ndiritu M, Ogutu B, Mithwani S, Maitland K, Berkley JA, Crawley J, Fegan G, Bauni E, Peshu N, Marsh K, Neville BGR, Newton CRJC: Burden, features and outcome of neurological involvement in acute falciparum malaria in Kenyan children. JAMA 2007, 297:2232-2240.

4. Isquith PK, Crawford JS, Espy KA, Gioia GA: Assessment of executive function in preschool-aged children. Ment Retard Dev Disabil Res Rev 2005, 11:209-215.

5. Holding PA, Stevenson J, Peshu N, Marsh K: Cognitive sequelae of severe malaria with impaired consciousness. Trans R Soc Trop Med and Hyg 1999, 93:529-534.

6. Kihara M, Carter JA, Holding PA, Vargha-Khadem F, Scott RC, Idro R, Fegan GW, Haan M, Neville BGR, Newton CRJC: Impaired everyday memory associated with encephalopathy of severe malaria: the role of seizures and hippocampal damage. Malar J 2009, 8:273.

7. Wilkins AJ, Shallice T, McCarthy R: Frontal lesions and sustained attention. Neuropsychologia 1987, 25:359-365.

8. Chan RC, Shum D, Toulopoulou T, Chen EY: Assessment of executive functions: review of instruments and identification of critical issues. Arch Clin Neuropsychol 2008, 23:201-216.

9. Newton CRJC, Hien T, White N: Cerebral malaria. J Neurol Neurosurg Psychiatry 2000, 69:433-441.

10. Banerjee TD, Middleton F, Faraone SV: Environmental risk factors for attention-deficit hyperactivity disorder. Acta Paediatr 2007, 96:1269-1274.

11. Idro R, Carter JA, Fegan G, Neville BG, Newton CR: Risk factors for persisting neurological and cognitive impairments following cerebral malaria. Arch Dis Child 2006, 91:142-148.

12. Seidman LJ, Buka SL, Goldstein JM, Horton NJ, Rieder RO, Tsuang MT: The relationship of prenatal and perinatal complications to cognitive functioning at age 7 in the New England Cohorts of the National Collaborative Perinatal Project. Schizophr Bull 2000, 26:309-321.

13. Abubakar A, Holding P, Van de Vijver FJ, Newton C, Van Baar A: Children at risk for developmental delay can be recognised by stunting, being underweight, ill health, little maternal schooling or high gravidity. J Child Psychol Psychiatry 2010, 51:652-659.

14. Bangirana P, Menk J, John CC, Boivin MJ, Hodges JS: The association between cognition and academic performance in Ugandan children surviving malaria with neurological involvement. PLoS One 2013 8:e55653.

15. Scott JAG, Bauni E, Moisi JC, Ojal J, Gatakaa H, Nyundo C, Molyneux CS, Kombe F, Tsofa B, Marsh K, Peshu N, Williams TN: Profile: the Kilifi Health and Demographic Surveillance System (KHDSS). Int J Epidemiol 2012, 41:650-657.
16. Berkley JA, Bejon P, Mwangi T, Gwer S, Maitland K, Williams TN, Mohammed S, Osier F, Kinyanjui S, Fegan G, Lowe BS, English M, Peshu N, Marsh K, Newton CR: HIV infection, malnutrition, and invasive bacterial infection among children with severe malaria. Clin Infect Dis 2009, 49:336-343.

17. Molyneux ME, Taylor TE, Wirima JJ, Borgstein A: Clinical features and prognostic indicators in paediatric cerebral malaria: a study of 131 comatose Malawian children. Q J Med 1989, 71:441-459.

18. Kariuki SM, Ikumi M, Ojal J, Sadarangani M, Idro R, Olotu A, Bejon P, Berkley JA, Marsh K, Newton CR: Acute seizures attributable to falciparum malaria in an endemic area on the Kenyan coast. Brain 2011, 134:1519-1528.

19. Idro R, Gwer S, Kahindi M, Gatakaa H, Kazungu T, Ndiritu M, Maitland K Neville BG, Kager PA, Newton CR: The incidence, aetiology and outcome of acute seizures in children admitted to a rural Kenyan district hospital. BMC Pediatr 2008, 8:5.

20. Musila N, Opiyo N, English M: Treatment of African children with severe malaria - towards evidence-informed clinical practice using GRADE. Malar J 2011, 10:201.

21. Kihara M, De Haan M, Garrashi HH, Neville BG, Newton CR: Atypical brain response to novelty in rural African children with a history of severe falciparum malaria. J Neurol Sci 2010, 296:88-95.

22. Kitsao-Wekulo PK, Holding PA, Taylor HG, Abubakar A, Connolly K: Neuropsychological testing in a rural African school-age population: evaluating contributions to variability in test performance. Assessment 2012, 20:776-784

23. Petrides $M$, Milner B: Deficits on subject-ordered tasks after frontal- and temporal-lobe lesions in man. Neuropsychologia 1982, 20:249-262.

24. Cerrone P, Mazzocco M, Cox C: Normative data for the contingency naming test (CNT). Arch Clin Neuropsychol 1999, 14:711.

25. Ballard JC: Computerized assessment of sustained attention: a review of factors affecting vigilance performance. J Clin Exp Neuropsychol 1996, 18:843-863.

26. Mitchell WG, Zhou Y, Chavez JM, Guzman BL: Reaction time, attention, and impulsivity in epilepsy. Pediatr Neurol 1992, 8:19-24.

27. Floden D, Alexander MP, Kubu CS, Katz D, Stuss DT: Impulsivity and risk-taking behavior in focal frontal lobe lesions. Neuropsychologia 2008, 46:213-223

28. Bangirana P, Musisi S, Boivin MJ, Ehnvall A, John CC, Bergemann TL, Allebeck P: Malaria with neurological involvement in Ugandan children: effect on cognitive ability, academic achievement and behaviour. Malar J 2011, 10:334

29. Idro R, Jenkins NE, Newton CR: Pathogenesis, clinical features, and neurological outcome of cerebral malaria. Lancet Neurol 2005, 4:827-840

30. Hesdorffer DC, Caplan R, Berg AT: Familial clustering of epilepsy and behavioral disorders: evidence for a shared genetic basis. Epilepsia 2012 53:301-307

31. Stretton J, Thompson PJ: Frontal lobe function in temporal lobe epilepsy. Epilepsy Res 2012, 98:1-13.

\section{doi:10.1186/1475-2875-13-365}

Cite this article as: Kariuki et al:: Impairment of executive function in Kenyan children exposed to severe falciparum malaria with neurological involvement. Malaria Journal 2014 13:365

\section{Submit your next manuscript to BioMed Central and take full advantage of:}

- Convenient online submission

- Thorough peer review

- No space constraints or color figure charges

- Immediate publication on acceptance

- Inclusion in PubMed, CAS, Scopus and Google Scholar

- Research which is freely available for redistribution 